\title{
Aditivos no tratamento de dejetos de poedeiras comerciais
}

\author{
Additives in the treatment of commercial laying hens manure \\ Aditivos en el tratamiento del estiércol de las gallinas ponedoras comerciales
}

Recebido: 15/12/2020 | Revisado: 24/12/2020 | Aceito: 06/01/2021 | Publicado: 07/01/2021

\author{
Danilo de Souza Sanches \\ ORCID: https://orcid.org/0000-0002-6579-1929 \\ Universidade Estadual de Mato Grosso do Sul, Brasil \\ E-mail: danilorzt9@gmail.com \\ Elis Regina de Moraes Garcia \\ ORCID: https://orcid.org/0000-0003-3739-2522 \\ Universidade Estadual de Mato Grosso do Sul, Brasil \\ E-mail: ermgarcia@hotmail.com \\ Patrícia Gomes Santana \\ ORCID: https://orcid.org/0000-0002-5553-9471 \\ Universidade Federal de Mato Grosso do Sul, Brasil \\ E-mail: patriciagsantanaa@gmail.com \\ Gislaine da Cunha de Andrade \\ ORCID: https://orcid.org/0000-0003-0239-1132 \\ Universidade Federal de Mato Grosso do Sul, Brasil \\ E-mail: andrade.gislaine.ga@gmail.com \\ Gustavo Ruivo Salmazzo \\ ORCID: https://orcid.org/0000-0002-7686-699X \\ Universidade Estadual de Mato Grosso do Sul, Brasil \\ E-mail: gustavodisalmazzo@gmail.com
}

\begin{abstract}
Resumo
Objetivou-se verificar o efeito do tratamento dos dejetos de poedeiras comerciais sobre o teor de matéria seca, o pH e a quantidade de amônia volatilizada. O delineamento experimental foi em blocos casualizados em esquema fatorial 4 x 5 (4 tipos de dejetos x 5 períodos) e quatro repetições. Avaliou-se: dejetos frescos (DF), DF + óxido de cálcio (500 g.m $\left.\mathrm{m}^{2}\right), \mathrm{DF}+$ sulfato de cálcio ( $40 \%$ do peso da cama) e DF + terra diatomácea $\left(200 \mathrm{~g} . \mathrm{m}^{2}\right)$, nos períodos 0 (antes da aplicação) e aos 4, 8, 12 e 16 dias após a aplicação. Observou-se que os dejetos tratados com óxido e sulfato de Cálcio apresentaram maiores teores de matéria seca em comparação ao controle. Verificou-se comportamento quadrático para o teor de matéria seca em função do período. $\mathrm{O}$ pH dos dejetos frescos e dejetos tratados com terra diatomácea não alterou durante os períodos analisados, no entanto, os dejetos tratados com óxido e sulfato de cálcio apresentaram comportamento quadrático ao longo dos 16 dias de avaliação para essa variável. Para a amônia volatilizada, os dejetos submetidos a aplicação de sulfato de cálcio e terra diatomácea não diferiram do controle até 12 dias após a aplicação. Contudo, a adição de óxido de cálcio nos dejetos promoveu efeito quadrático para essa variável durante todo período experimental. A adição de sulfato de cálcio aos dejetos de poedeiras reduz a umidade e o pH e inibe a volatilização da amônia por até 12 dias. Após este período recomenda-se uma nova aplicação.
\end{abstract}

Palavras-chave: Amônia volatilizada; Avicultura; Condicionantes; Resíduos de aves.

\begin{abstract}
The objective of this study was to determine the dry matter, $\mathrm{pH}$ and volatilized ammonia of fresh waste from commercial laying hens treated or not with different additives. The experimental design was randomized in factorial scheme 4 x 5 (4 types of waste x 5 periods) and four replications. It has assessed: fresh waste (DF), DF + calcium oxide (500 g.m2), DF + calcium sulfate ( $40 \%$ of bed weight) and DF + diatomaceum earth ( 200 g.m2), in periods 0 (before application) and 4, 8, 12 and 16 days after application. It was observed that the waste treated with calcium oxide and sulfate showed higher dry matter contents compared to the control. There was a quadratic behavior for the dry matter content as a function of the period. The $\mathrm{pH}$ of fresh waste and waste treated with diatomaceous earth did not change during the periods analyzed, however, the waste treated with oxide and calcium sulfate showed quadratic behavior over the 16 days of evaluation for this variable. For volatilized ammonia, the waste submitted to calcium sulfate and diatomaceous earth did not differ from the control until 12 days after application. However, the addition of calcium oxide in the wastes promoted a quadratic effect for this variable throughout the experimental period. The use of calcium sulfate to laying hens waste reduces moisture and $\mathrm{pH}$ and inhibits ammonia volatilization for up to 12 days. After this period a new application is recommended.
\end{abstract}

Keywords: Conditioning factors; Poultry; Poultry waste; Volatilized ammonia. 


\section{Resumen}

El objetivo de este estudio fue determinar la materia seca, el pH y el amoníaco volatilizado de los residuos frescos de gallinas ponedoras comerciales tratadas o no con diferentes aditivos. El diseño experimental fue aleatorizado en un esquema factorial 4 x 5 (4 tipos de residuos x 5 períodos) y cuatro replicaciones. Se evaluaron los siguientes: residuos frescos (DF), DF + óxido de calcio (500 g.m2), DF + sulfato de calcio (40\% del peso del lecho) y DF + tierra diatomacea (200 g.m2), en períodos 0 (antes de la aplicación) y a los 4, 8, 12 y 16 días después de la aplicación. Se observó que los residuos tratados con óxido de calcio y sulfato mostraban un mayor contenido de materia seca en comparación con el control. fue encontrado comportamiento cuadrático para el contenido de materia seca en función del período. El pH del estiércol fresco y del estiércol tratado con tierra diatomeas no varió durante los períodos analizados, sin embargo, el estiércol tratado con óxido y sulfato de calcio mostró un comportamiento cuadrático durante los 16 días de evaluación para esta variable. Para el amoniaco volatilizado, los desechos sometidos a la aplicación de sulfato de calcio y tierra diatomeas no difirieron del control hasta 12 días después de la aplicación. Sin embargo, la adición de óxido de calcio en los residuos promovió un efecto cuadrático para esta variable a lo largo del período experimental. La adición de sulfato de calcio a los residuos de gallinas ponedoras reduce la humedad y el pH e inhibe la volatilización del amoníaco durante un máximo de 12 días. Después de este período se recomienda una nueva aplicación.

Palabras clave: Amoníaco volatilizado; Avicultura; Factores de acondicionamiento; Residuos de aves.

\section{Introdução}

Com o desenvolvimento avícola, o aumento da densidade de alojamento das aves resulta proporcionalmente no acréscimo da produção de dejetos, que, se tratados de maneira incorreta, emitem gases de efeito estufa (GEEs) como a amônia, o dióxido de carbono e o metano que podem gerar diversos danos aos animais, como por exemplo, perda de peso, irritação nos olhos, queda de produção pela incidência de doenças e problemas respiratórios. Nos humanos pode causar tosse, dificuldade respiratória, secreção de saliva, retenção de urina, irritação nos olhos e pele, cegueira temporária, edema pulmonar e até mesmo a morte (Sousa et al. 2016, Farias et al. 2012). Os GEEs também afetam negativamente o meio ambiente, pois potencializam a degradação da camada de ozônio e o aquecimento global (Silva et al. 2020).

As rações fornecidas para poedeiras contém alto conteúdo proteico e o nitrogênio $(\mathrm{N})$, quando não metabolizado pelo animal, é excretado na forma de ácido úrico juntamente aos dejetos. Este composto sofre ação microbiana que, quando associado a fatores ambientais, químicos e enzimáticos, libera amônia $\left(\mathrm{NH}_{3}\right)$ para o ar atmosférico. A $\mathrm{NH}_{3}$ é um gás incolor que apresenta elevado poder poluente (Oliveira \& Monteiro, 2013).

Neste contexto, o $\mathrm{N}$ que está presente nas dejeções de aves tornou-se um problema para indústria avícola mundial (França, 2014) e a adoção de estratégias adequadas de controle do ambiente interno dos galpões avícolas através de ventilação correta, manejo da cama e dejetos, uso de aditivos capazes controlar o teor de nitrogênio fornecido via ração, vem sendo utilizadas para reduzir a emissão de amônia (Souza et al. 2016). A utilização de aditivos sobre os dejetos de poedeiras ou cama de frango é uma das soluções mais práticas e baratas que pode minimizar os efeitos nocivos dos gases no interior dos galpões avícola (Oliveira \& Monteiro, 2013).

Entre os produtos que podem ser utilizados para este fim estão o sulfato de cálcio $\left(\mathrm{CaSO}_{4} \cdot 2 \mathrm{H}_{2} 0\right)$, óxido de cálcio $(\mathrm{Ca}$ $\left.(\mathrm{OH})^{2}\right)$, dióxido de sílica ou terra diatomácea, sulfato de alumínio, bissulfato de sódio, argila acidificada, superfosfato simples e outros. Todos esses produtos promovem alterações no $\mathrm{pH}$, reduzem o excesso de umidade da cama e minimizam a emissão de gases indesejáveis (amônia), propiciando um meio desfavorável para o desenvolvimento de microrganismos patogênicos para a produção avícola (Lucca et al. 2012, Oliveira et al. 2004, Mcward \& Taylor, 2000).

Deste modo, este trabalho foi realizado com o objetivo de verificar o efeito do tratamento dos dejetos de poedeiras comerciais sobre o teor de matéria seca, o pH e a quantidade de amônia volatilizada. 


\section{Metodologia}

O experimento foi desenvolvido no Centro de Produção Zootécnica (CDPZ) de avicultura da Universidade Estadual de Mato Grosso do Sul, Unidade Universitária de Aquidauana. Geograficamente, a região está localizada entre as coordenadas $20^{\circ} 28^{\prime}$ s latitude e $55^{\circ} 48^{\prime} \mathrm{W}$ longitude, a uma altitude de 174 metros. Foram alojadas 96 poedeiras comerciais em gaiolas de arame galvanizado $(0,45 \mathrm{~m} \times 0,5 \mathrm{~m} \times 1 \mathrm{~m})$, em galpão convencional de postura com cobertura de telhas de barro e piso de concreto.

As gaiolas eram dotadas de bebedouros tipo nipple e comedouros tipo calha. As aves receberam a mesma ração durante todo o período experimental, às 8h:00 e 16h:00, na quantidade de $107 \mathrm{~g} /$ ave dia. O programa de iluminação adotado foi de 17 horas por dia (luz natural + artificial).

O delineamento experimental adotado foi em blocos casualizados em esquema fatorial 4 x 5 (4 tipos de dejetos x 5 períodos) e quatro repetições. Os tipos de dejetos foram: $\mathrm{T} 1=$ dejetos frescos (DF) sem tratamento; $\mathrm{T} 2=$ dejetos frescos tratados com óxido de cálcio (cal virgem - $500 \mathrm{~g} / \mathrm{m}^{2}$ ); $\mathrm{T} 3$ = dejetos frescos tratados com sulfato de cálcio (gesso agrícola $40 \%$ peso cama); $\mathrm{T} 4=$ dejetos frescos tratados com terra diatomácea $\left(200 \mathrm{~g} / \mathrm{m}^{2}\right)$.

Foram realizadas três aplicações dos respectivos aditivos sobre os dejetos produzidos pelas poedeiras comerciais no período do verão, nos meses de dezembro de 2017 a março de 2018, simulando o manejo em condições comerciais de criação. Após a aplicação dos aditivos, os dejetos foram coletados e analisados em diferentes períodos, antes da adição (dia zero) e aos $4,8,12$, e 16 dias após tratamento. As três aplicações foram consideradas como critério de bloqueamento para formação dos blocos.

Para as análises, as amostras foram coletadas aleatoriamente em diferentes pontos sob a gaiola, evitando áreas embaixo de bebedouros e comedouros. Em cada um dos tempos as amostras foram coletadas, homogeneizadas e acondicionadas em sacos plásticos para realização das análises de matéria seca, $\mathrm{pH}$ e amônia volatilizada. Para a determinação da matéria seca foi aplicada a metodologia descrita por Silva \& Queiroz (2006). A determinação da amônia liberada pelos dejetos frescos foi realizada de acordo com a metodologia proposta por Hernandes e Cazetta (2001). Para permitir a fixação de grandes quantidades de amônia titulável, as amostras foram coletadas, organizadas e incubadas pela manhã, permanecendo incubadas durante o período da tarde e da noite para serem tituladas na manhã seguinte, totalizando um tempo de incubação de 24 horas.

Para a mensuração do $\mathrm{pH}$ foram coletados $30 \mathrm{~g}$ de cada repetição e logo em seguida as amostras foram homogeneizadas em béquer, diluídas com $250 \mathrm{ml}$ de água deionizada e agitadas por 5 minutos. Após esses processos, cada amostra foi deixada por 30 minutos em repouso e então foi realizada a leitura no $\mathrm{pH}$-metro digital.

Os dados foram submetidos à análise de variância para verificar os efeitos dos fatores estudados, para o fator período foi realizado análise de regressão. Quando houve efeito significativo de interação $(P<0,05)$ efetuou-se o desdobramento dos fatores, já para as variáveis que não apresentaram efeito de interação adotou-se o efeito isolado dos fatores $(\mathrm{P}<0,05)$, aplicado o Teste de Tukey para a comparação das médias.

\section{Resultados e Discussão}

Os dados referentes aos teores de matéria seca (MS), $\mathrm{pH}$ e amônia volatilizada dos dejetos de poedeiras comerciais tratados ou não com diferentes aditivos estão apresentados na Tabela 1. Verificou-se efeito significativo dos tratamentos para matéria seca, de forma que os dejetos tratados com óxido e sulfato de cálcio apresentaram valores superiores ao controle, por outro lado, os dejetos tratados com terra diatomácea não diferiram dos demais tratamentos.

Esse resultado evidencia que o óxido de cálcio e sulfato de cálcio foram efetivos em manter os dejetos em boas condições em termos de umidade, já que ambos possuem grande capacidade de retenção de água (Rodrigues et al. 2003). O 
oxido de cálcio quando presente em meio aquoso é hidrolisado por meio da reação química $\left(\mathrm{CaO}+\mathrm{H}_{2} \mathrm{O} \rightarrow \mathrm{Ca}(\mathrm{OH})_{2}\right)$ que é exotérmica, a água ao reagir com o mesmo promove a formação de hidróxido de cálcio que é um composto básico. Neste processo a água pode ser consumida ou evaporada causando a redução da umidade do meio, justificando o efeito adsorvente do oxido de cálcio.

Tabela 1. Teores de matéria seca, $\mathrm{pH}$ e amônia volatilizada de dejetos de poedeiras comerciais tratados ou não com diferentes aditivos.

\begin{tabular}{|c|c|c|c|}
\hline \multirow[b]{2}{*}{ Tipos de tratamentos } & \multicolumn{3}{|c|}{ Variáveis } \\
\hline & Matéria Seca (\%) & $\mathrm{pH}$ & $\begin{array}{l}\text { Amônia Volatilizada } \\
\left(\mathrm{mg} .100 \mathrm{~g}^{-1} .24 \text { horas }^{-1}\right)\end{array}$ \\
\hline $\mathrm{DF}$ & $38,99 b$ & 8,31 & 2,73 \\
\hline $\mathrm{OC}$ & $42,27 \mathrm{a}$ & 8,83 & 4,04 \\
\hline $\mathrm{SC}$ & $41,73 a$ & 7,82 & 2,13 \\
\hline $\mathrm{TD}$ & $40,97 \mathrm{ab}$ & 8,32 & 2,58 \\
\hline $\mathrm{CV} \%$ & 13,90 & 3,85 & 40,16 \\
\hline Período (dias) & Quadrático & Quadrático & Quadrático \\
\hline 0 & 37,28 & 8,32 & 2,48 \\
\hline 4 & 39,87 & 8,44 & 2,81 \\
\hline 8 & 44,79 & 8,44 & 2,78 \\
\hline 12 & 41,63 & 8,29 & 3,31 \\
\hline \multirow[t]{2}{*}{16} & 41,39 & 8,27 & 3,22 \\
\hline & & Valores de & \\
\hline Bloco & $<0,01$ & $<0,05$ & $<0,05$ \\
\hline Tratamento & $<0,01$ & $<0,05$ & $<0,05$ \\
\hline Período & $<0,01$ & $<0,05$ & $<0,01$ \\
\hline Tratamento*Período & 0,366 & $<0,05$ & $<0,05$ \\
\hline
\end{tabular}

Médias seguidas de letras diferentes, nas colunas, diferem $(\mathrm{P}<0,05)$ pelo teste de Tukey; DF: Dejetos Frescos; OC: Óxido de cálcio; SC: Sulfato de cálcio; TD: Terra diatomácea. Fonte: Autores.

Foi observado comportamento quadrático para o teor de matéria seca em função do período, porém, não foi constatado interação significativa entre os fatores estudados para esta variável. O teor de MS dos dejetos de aves aumentou à medida que os dias de acúmulo do resíduo nas instalações foram prolongados, com ponto de máxima (43,21\%) aos 10,04 dias após tratamento do dejeto (Figura 1).

Resultados encontrados por Lucca et al. (2012), evidenciaram que todos os tratamentos químicos avaliados (hidróxido de cálcio $\left(500 \mathrm{~g} / \mathrm{m}^{2}\right)$, Sulfato de alumínio $\left(500 \mathrm{~g} / \mathrm{m}^{2}\right)$, Sulfato de cálcio $\left(1000 \mathrm{~g} / \mathrm{m}^{2}\right)$, Sulfato de cálcio $48 \%+$ Filosilicato expandido $28 \%\left(500 \mathrm{~g} / \mathrm{m}^{2}\right)$ ) em cama nova (maravalha) de frangos de corte foram eficazes na absorção de umidade na primeira e na segunda semana de criação das aves, após esse período, a medida que os animais cresciam o volume das fezes aumentavam o que elevou a perda de eficiência dos produtos.

Por outro lado, Oliveira et al. (2003) ao estudarem os teores de matéria seca, pH e quantidade de amônia volatilizada da cama (casca de arroz) de frango tratada ou não com diferentes aditivos (cama nova, cama reutilizada sem tratamento, cama reutilizada tratada com sulfato de alumínio, cama reutilizada tratada com gesso agrícola - 40\% peso da cama e cama reutilizada tratada com cal hidratada $-0,5 \mathrm{Kg} / \mathrm{m}^{2}$ ), observaram que ao final do $42^{\circ}$ dia de criação, os tratamentos não interferiram nos teores de matéria seca, diferindo dos resultados encontrados neste estudo. 
Figura 1. Percentual de matéria seca de dejetos de poedeiras tratados ou não com diferentes aditivos pelo período de 16 dias.

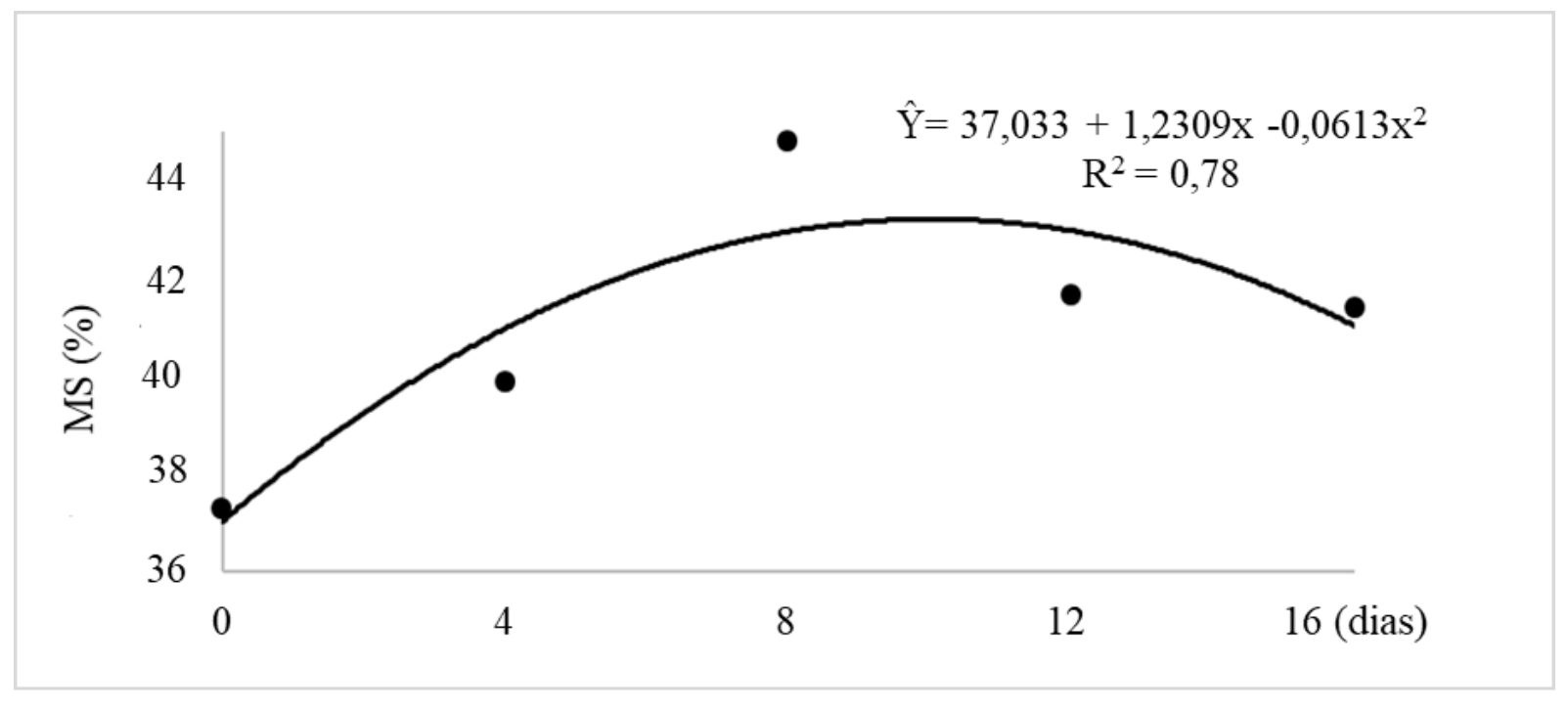

Fonte: Autores.

Segundo os autores, a cama usada passou por vários revolvimentos para ser utilizada, deixando-as com baixo teor de umidade não evidenciando o efeito dos tratamentos, diferente deste trabalho, na qual utilizou-se os dejetos frescos de poedeiras comerciais com elevado teor de umidade.

Constatou-se por meio da interação $(\mathrm{P}<0,05)$ que o controle e a adição de terra diatomácea não alteraram o pH dos dejetos ao longo dos períodos avaliados, por outro lado, o pH dos dejetos tratados com óxido de cálcio e sulfato de cálcio apresentaram comportamento quadrático ao longo dos 16 dias de avaliação, com ponto de máximo $(9,18)$ e mínimo $(7,78)$ aos 8,2 e 10,3 dias, respectivamente, após o tratamento (Tabela 2).

Dentro de cada período avaliado, os maiores valores de $\mathrm{pH}$ foram verificados para os dejetos tratados com óxido de cálcio, possivelmente porque o óxido de cálcio é uma substância alcalina e em contato com os dejetos pode ter elevado o pH (Oliveira et al. 2003). Constatou-se que a adição de óxido de cálcio manteve elevado o pH dos dejetos até 8,2 dias após a inclusão do aditivo e, após esse período os valores de pH reduziram (Figura 2), demonstrando que o aumento da dissociação do íon $\mathrm{H}+$ durante o processo de formação da amônia e o acúmulo de excretas nas unidades experimentais durante o período, provavelmente reduziu o efeito do produto e, consequentemente, o $\mathrm{pH}$ dos dejetos.

Tabela 2. Valores médios de $\mathrm{pH}$ de dejetos de poedeiras comerciais tratados ou não com diferentes aditivos no período de 16 dias.

\begin{tabular}{ccccccccc}
\hline \multirow{2}{*}{$\begin{array}{c}\text { Tipos de } \\
\text { tratamentos }\end{array}$} & \multicolumn{9}{c}{ Períodos (dias) } & & Equação de Regressão & $\mathrm{R}^{2}$ & $P$ value \\
\cline { 2 - 8 } & 0 & 4 & 8 & 12 & 16 & - \\
\hline DF & 7,70 & $8,39 \mathrm{~b}$ & $8,33 \mathrm{~b}$ & $8,25 \mathrm{~b}$ & $8,26 \mathrm{~b}$ & $\hat{\mathrm{Y}}=8,31$ & - \\
OC & 7,53 & $9,23 \mathrm{a}$ & $9,23 \mathrm{a}$ & $8,73 \mathrm{a}$ & $8,66 \mathrm{a}$ & $\hat{\mathrm{Y}}=8,4468+0,1787 \mathrm{x}-0,0109 \mathrm{x}^{2}$ & 0,70 & $<0,01$ \\
SC & 7,98 & $7,81 \mathrm{c}$ & $7,87 \mathrm{c}$ & $7,87 \mathrm{c}$ & $7,89 \mathrm{c}$ & $\begin{array}{c}\mathrm{Y}=8,2579-0,0926 \mathrm{x}+ \\
0,0045 \mathrm{x}^{2}\end{array}$ & 0,78 & $<0,01$ \\
TD & 7,80 & $8,34 \mathrm{~b}$ & $8,35 \mathrm{~b}$ & $8,31 \mathrm{~b}$ & $8,28 \mathrm{~b}$ & $\hat{\mathrm{Y}}=8,32$ & - \\
\hline
\end{tabular}

Médias seguidas de letras diferentes, nas colunas, diferem $(\mathrm{P}<0,01)$ pelo teste de Tukey; DF: Dejetos Frescos; OC: Óxido de cálcio; SC: Sulfato de Cálcio; TD: Terra diatomácea. Fonte: Autores. 
Resultados semelhantes foram encontrados por Daí Pra et al. (2009) que avaliaram o pH da cama (maravalha reutilizada) de frango tratadas ou não com oxido de cálcio $\left(300,600\right.$ e $\left.900 \mathrm{mg} / \mathrm{m}^{2}\right)$ após doze dias de alojamento, e verificaram pH alcalino nas amostras avaliadas, da mesma forma, Rodrigues et al. (2003), ao determinarem o pH da cama de frango tratada ou não com diferentes aditivos, concluíram que a cama tratada com a cal manteve o pH elevado, por ser uma substância alcalina.

Os menores valores de $\mathrm{pH}$ determinados nos dejetos tratados com sulfato de cálcio, podem estar relacionados com a alta quantidade de aditivo utilizado ( $40 \%$ do peso da cama) e de sua grande capacidade de absorção de umidade e fixação de nitrogênio que fez com que ocorresse a diminuição do $\mathrm{pH}$.

De acordo com os resultados contatou-se que a inclusão de sulfato de cálcio nos dejetos, promoveu a redução do pH até os 10,3 dias após o tratamento, após esse período os valores de pH aumentaram, tal fato condiz com o resultado de matéria seca $(\%)$ dos dejetos tratados com sulfato de cálcio destacados anteriormente, uma vez que, as excretas submetidas a este tratamento apresentaram redução de percentual de matéria seca em períodos (10,4 dias) similares ao aumento de pH, respaldando assim, a influência da umidade sobre o $\mathrm{pH}$ dos dejetos analisados neste trabalho.

Da mesma forma, Neme et al. (2000), ao estudarem o efeito da utilização do gesso agrícola no tratamento da cama aviária, verificaram redução no pH das camas. A estabilização do pH inferior a 7,5 e a presença de íons H+ na cama é muito importante para a manutenção da relação amônio: amônia, ou seja, uma elevada quantidade de amônia é convertida a íon amônio que não é volátil (Toppel et al. 2018). Em contrapartida, o pH acima de 8,0 e o alto nível de umidade na cama estimulam o desenvolvimento bacteriano e aceleram o processo biológico de decomposição do ácido úrico pela enzima uricase, elevando a produção de NH3 (amônia) que é volátil (Weiss 2015, França et al. 2014).

Tabela 3. Concentração de amônia volatilizada $\left(\mathrm{mg} \cdot 100 \mathrm{~g}^{-1}\right.$. 24 horas $\left.^{-1}\right)$ nos dejetos de poedeiras comerciais tratados ou não com diferentes aditivos determinada no período de16 dias.

\begin{tabular}{|c|c|c|c|c|c|c|c|c|}
\hline \multirow[t]{2}{*}{$\begin{array}{c}\text { Tipos de } \\
\text { tratamentos }\end{array}$} & \multicolumn{5}{|c|}{ Períodos (dias) } & \multirow[t]{2}{*}{ Equação de regressão } & \multirow[t]{2}{*}{$\mathrm{R}^{2}$} & \multirow[t]{2}{*}{$P$ value } \\
\hline & 0 & 4 & 8 & 12 & 16 & & & \\
\hline DF & $1,84 b$ & $2,730 \mathrm{~b}$ & $2,421 b$ & $2,999 b$ & $3,262 b$ & $\hat{\mathrm{Y}}=2,787$ & - & - \\
\hline OC & $0,94 b$ & $4,389 a$ & $4,241 \mathrm{a}$ & $4,705 \mathrm{a}$ & $4,712 \mathrm{a}$ & $\begin{array}{c}\hat{Y}=2,6947+0,3473 x- \\
0,0142 x^{2}\end{array}$ & 0,87 & 0,01 \\
\hline $\mathrm{SC}$ & $0,90 \mathrm{~b}$ & $1,991 b$ & $1,903 b$ & $2,462 b$ & $1,983 \mathrm{c}$ & $\hat{\mathrm{Y}}=2,164$ & - & - \\
\hline TD & $1,76 b$ & $2,116 b$ & $2,549 \mathrm{~b}$ & $3,078 b$ & $2,915 b c$ & $\hat{Y}=2,627$ & - & - \\
\hline
\end{tabular}

Médias seguidas de letras diferentes, nas colunas, diferem $(\mathrm{P}<0,01)$ pelo teste de Tukey; DF: Dejetos Frescos; OC: Óxido de cálcio; SC: Sulfato de Cálcio; TD: Terra diatomácea. Fonte: Autores.

Para a amônia volatilizada não houve diferença significativa entre os dejetos frescos e dejetos que receberam a aplicação de sulfato de cálcio e terra diatomácea até 12 dias, após esse período, os dejetos tratados com sulfato de cálcio diferiram-se do controle (Tabela 3), o que é interessante. Analisando os resultados do presente estudo, é evidente que o sulfato de cálcio foi eficiente em controlar a umidade e $\mathrm{pH}$ dos dejetos, por aproximadamente 11 dias, no entanto, para amônia volatilizada não foi observado o mesmo efeito. A provável explicação deve-se ao fato de que, além da eficiência sobre a MS e $\mathrm{pH}$, ocorreu o acúmulo de dejetos abaixo das gaiolas o que aumentou a espessura da camada dos dejetos no piso, dificultando as trocas gasosas com a atmosfera interna do galpão, favorecendo a redução da volatilização de amônia (Hernandez \& Cazetta, 2001), principalmente após 12 dias.

A adição de óxido de cálcio nos dejetos promoveu efeito quadrático sobre a concentração de amônia volatilizada 
durante todo período experimental, com ponto de máximo de volatilização aos 12,23 dias após o tratamento. Este resultado ocorreu em função do $\mathrm{pH}$ ter sido mais elevado nos dejetos submetidos a adição de óxido de cálcio, já que o pH da cama tem relação direta sobre as quantidades de amônia que é volatilizada para o ambiente, ou seja, a volatilização é reduzida conforme a diminuição do pH, e aumenta à medida que o pH se eleva (Rodrigues et al. 2003). Li et al. (2006) confirmam que o pH é um fator determinante para a produção de amônia nos aviários, pois a ativação da enzima uricase que é responsável pela reação de decomposição do ácido úrico excretado pelas aves, que tem seu ponto ótimo de atuação em pH (8,5 - 9), ou seja, em meio alcalino.

A redução da umidade dos dejetos promovida pelo tratamento de óxido de cálcio provavelmente não foi suficiente para impedir a atuação das bactérias mineradoras do ácido úrico. Tal fato, associado à capacidade do produto em elevar o pH do dejeto favoreceu o processo de decomposição do ácido úrico excretado pelas aves que, consequentemente, acelerou a produção e volatilização da amônia para o ambiente.

\section{Conclusão}

A adição de sulfato de cálcio nos dejetos de poedeiras comerciais (40\% do peso) reduz a umidade e o pH baixo, e inibe a volatilização de amônia para o ambiente por até 12 dias após o tratamento, entretanto, após este período recomenda-se uma nova aplicação. No verão o uso de óxido de cálcio também pode ser uma ótima opção para controlar a umidade dos dejetos, porém é necessário analisar o valor do produto antes de tomar essa decisão. A terra diatomácea é um produto inovador, assim sua utilização em maiores quantidades de aplicação pode ser uma tendência para estudos futuros que buscam alterar o pH, umidade e volatilização da amônia de dejetos de aves.

\section{Referências}

Dai Pra, P. A., Corrêa, É. K., Roll, V. F., Xavier, E. G., Lopes, D. C. N., Lourenço, J. T., \& Roll, A. P. (2009). Uso de cal virgem para o controle de Salmonella spp e Clostridium spp em camas de aviário. Ciência Rural, 39 (4), 1189-1194. https://doi.org/10.1590/S0103-84782009005000028.

Farias, R. M., Orrico Junior, M. A. P. O., Orrico, A. C. A., Garcia, R. G., Centurion, S. R., \& Fernandes, A. R. M. (2012). Biodigestão anaeróbia de dejetos de poedeiras coletados após diferentes períodos de acúmulo. Ciência rural, 42 (6), 1089-1094. https://doi.org/10.1590/S0103-84782012005000031.

França, L. G. F. (2014). Variáveis de influência e proposição de índice de máxima emissão de amônia pela atividade de criação de galinhas poedeiras para o estado de minas gerais. Dissertação (Magister Scientiae). Universidade Federal de Viçosa. Minas Gerais.

França, L. G. F., Tinôco, I. F. F., Mendes, M. A. S. A., \& Coelho, D. J. R. (2014). Caracterização de fatores que influenciam a emissão de amônia pelos dejetos de galinhas poedeiras e proposição de um score para o potencial máximo de emissão. In: XLIII Congresso Brasileiro de Engenharia Agrícola. Anais... Campo Grande: CONBEA (Vol. 2014).

Hernandes, R., \& Cazetta, J. O. (2001). Método simples e acessível para determinar amônia liberada pela cama aviária. Revista Brasileira de Zootecnia, Viçosa, 30 (3), 824-829. https://doi.org/10.1590/S1516-35982001000300030.

Li, H. Ammonia emissions from manure belt laying hen houses and manure storage. (2006). Retrospective Theses and Dissertations of Iowa State University. Retrieved from https://lib.dr.iastate.edu/rtd/1273.

Lucca, W., Cecchin, R., Timbola, E., Gradin, J., \& Lucca, M. S (2012). Efeito de diferentes tratamentos químicos em cama para aves de corte. Revista Agrogeoambiental, 4 (1), 25-31. http://dx.doi.org/10.18406/2316-1817v4n12012371.

Mcward, G. W., \& Taylor, D. R (2000). Acidified clay litter amendment. Journal of Applied Poultry Research, 9 (4), 518-529. https://doi.org/10.1093/japr/9.4.518.

Neme, R., Sakomura, N. K., Oliveira, M. S., Longo, F. A., \& Figueiredo, A. N. (2000). Adição de gesso agrícola em três tipos de cama de aviário na fixação de nitrogênio e no desempenho de frango de corte. Ciência Rural, 30 (4), 687-692. http://dx.doi.org/10.1590/S0103-84782000000400022.

Oliveira, M. C., Almeida, C. V., Andrade, D. O., \& Rodrigues, S. M. M. (2003). Teor de Matéria Seca, pH e Amônia Volatilizada da Cama de Frango Tratada ou Não com Diferentes Aditivos. Revista Brasileira de Zootecnia, 32 (4), 951-954. https://doi.org/10.1590/S1516-35982003000400022.

Oliveira, M. C., Ferreira, H. A., \& Cancherini, L. C. (2004). Efeito de condicionadores químicos sobre a qualidade da cama de frango. Arquivo brasileiro de medicina veterinária e Zootecnia, 56 (4), 536-541. https://doi.org/10.1590/S0102-09352004000400016.

Oliveira, P. A. V., \& Monteiro, A. N. T. R. (2013). Emissão de amônia na produção de frangos de corte. In Embrapa Suínos e Aves-Artigo em anais de congresso (ALICE). In: Conferência FACTA, Campinas, 2013. Anais... Campinas: Facta, 2013. 1 CD-ROM. 
Research, Society and Development, v. 10, n. 1, e19410111229, 2021

(CC BY 4.0) | ISSN 2525-3409 | DOI: http://dx.doi.org/10.33448/rsd-v10i1.11229

Rodrigues, S. M. M., Oliveira, M. C., Almeida, C. V., \& Andrade, D. O. (2003). Teor de Matéria Seca, pH e amônia volatilizada da Cama de Frango Tratada ou não com Diferentes Aditivos. Revista Brasileira de Zootecnia, 32 (4), 951-954. https://doi.org/10.1590/S1516-35982003000400022.

Silva, A. A., Schmitt Filho, A. L., Kazama, D. C. S., Loss, A., Souza, M., Piccolo, M. C., Farley, J., \& Sinisgalli, P. A. A. (2020). Estoques de carbono e nitrogênio no Sistema Silvipastoril com Núcleos: a nucleação aplicada viabilizando a pecuária de baixo carbono. Research, Society and Development, 9 (10), e2799108589. http://dx.doi.org/10.33448/rsd-v9i10.8589.

Silva, D. J., \& Queiroz, A. C. (2006). Análise de alimentos: métodos químicos e biológicos (3a ed.), Editora Universitária.

Sousa, F. C., Tinôco, I. F. F., Paula, M. O., Silva, A. L., Souza, C. F., Batista, F. J. F., \& Barbari, M. (2016). Medidas para minimizar a emissão de amônia na produção de frangos de corte: revisão. Brazilian Journal of Biosystems Engineering, 10 (1), 51-61. http://dx.doi.org/10.18011/bioeng2016v10n1p51-61.

Toppel, K., Kaufmann, F., Schön, H., Gauly, M. \& Andersson, R. (2019). Effect of pHlowering litter amendment on animal-based welfare indicators and litter quality in a European commercial broiler husbandry. Poultry Science. 98(3), 1181-1189. https://doi.org/10.3382/ps/pey489.

Weiss, A. (2015). Effects of acidic litter amendments with multiple application on ammonia, microbial environment, production performances, and health of broilers (Doctoral dissertation, University of Delaware). http://udspace.udel.edu/handle/19716/17403. 